\title{
Gastric Intestinal Metaplasia: Prevalence, Clinical Presentation, Endoscopic and Histological Features
}

\author{
Drasovean Silvia Cosmina ${ }^{1 *}$, Morărașu Diana Elena², Pascarenco Ofelia Daniela², Brsunic Olga ${ }^{1,2}$, Onișor \\ Danusia Maria1,2, Boeriu Alina1,2, Dobru Daniela Ecaterina ${ }^{1,2}$ \\ University of Medicine and Pharmacy, Tirgu Mures \\ 2 Department of Gastroenterology, Mures County Hospital
}

Background and Aim: Gastric intestinal metaplasia represents a risk factor for intestinal type of gastric cancer. Gastric intestinal metaplasia seems to be associated with Helicobacter pilory infection in relatives of patients with gastric cancer. The aim of this study was to determine the prevalence, clinical, endoscopic and histological features of gastric intestinal metaplasia.

Material and Methods: We retrospectively analyzed the esophagogastroduodenoscopies with biopsies performed between January 1 , 2014 and October 31, 2014. Collected and analyzed data included age, gender, symptoms, endoscopic and histological findings.

Results: Four hundred eighty-two patients were included in the study. One hundred thirty-seven patients had gastric intestinal metaplasia, which presented a prevalence was $28,4 \%$. A similar distribution between gender was observed with a significant increase of gastric intestinal metaplasia with age $(p=0,0001)$. Regarding the indication for endoscopy, the prevalence of gastric intestinal metaplasia was: $17 \%$ among patients with dyspeptic syndrome, $2 \%$ in patients with anemia and $5 \%$ in patients examined for other symptoms. Endoscopic findings showed gastric intestinal metaplasia was significantly associated with atrophic gastritis $(p=0.0001)$, erythematous gastritis ( $p=0.0079)$, while there was no association with erosive gastritis $(p=0.24)$ and peptic ulcer $(p=0.19)$.

Conclusions: Gastric intestinal metaplasia is frequently recorded in patients undergoing in esophagogastroduodenoscopies with associated biopsies. Endoscopic findings like erythema and atrophy is strongly associated with gastric intestinal metaplasia emphasizing the importance of sampling biopsies.

Keywords: Helicobacter pylori, gastric intestinal metaplasia, gastric cancer

Received: 09 December 2014 / Accepted: 26 April 2015

\section{Introduction}

Gastric cancer is the second most frequent cause of cancerrelated mortality worldwide [1]. More than $95 \%$ of the total number of malignancies are adenocarcinoma [2]. According to Lauren classification [3] gastric cancer is divided into 2 major histologic types: intestinal and diffuse. Evidence shows that the pathogenesis of gastric cancer, particularly the intestinal-type, involves a series of sequential phases from gastritis associated with persistent Helicobacter pylori infection which may progress towards chronic atrophic gastritis, intestinal metaplasia and dysplasia to invasive carcinoma $[4,5]$. Thus gastric intestinal metaplasia is considered a precancerous lesion, increasing the risk of developing gastric cancer by 6 -fold. Intestinal metaplasia seems to be more frequently encountered in relatives of patients with gastric patients, in elderly patients and in case of infections with Helicobacter pilory. [6]. According to recent studies, annual endoscopic follow-up performed in patients with gastro-intestinal metaplasia coul detect gastric cancer in an early stage, leading to a significant improvement of the clinical evolution and increase in survival rates. [7].

The aim of this study was to determine the prevalence, clinical, endoscopic and histological features of gastric intestinal metaplasia.

* Correspondence to: Silvia Cosmina Drasovean

E-mail: silvianemes79@yahoo.com

\section{Materials and methods}

This was a retrospective review of the esophagogastroduodenoscopies with biopsies performed between January 1, 2014 and October 31, 2014 in the Endoscopic Unit at Mures County Hospital. Data including age, gender, symptoms, endoscopic and histological findings were collected for the study.

\section{Endoscopic and histological evaluation}

All the endoscopic examinations were performed by trained endoscopists, using an Olympus Exera video-endoscope. An informed consent to undergo endoscopy was obtained from all the patients and the study was approved by the ethics and scientific review committee of the institution. Biopsy specimens were fixed in formalin solution and embedded in paraffin. For the histopatological evaluation, the Giemsa, Hematoxylin- Eosin, PAS- Alcian Blue stains were performed. Helicobacter pylori infection was determined only by histological examination of biopsies.

\section{Statistical Methods:}

Data were tabled and analyzed using Microsoft Excel software (Microsoft Corporation, WA, USA). All statistical analyses were performed using GraphPad Software, CA, USA. Data were compared by using the chi-square test, and $\mathrm{P}$ value of $<0,05$ was considered statistical significant. Fisher's exact test was used when the values in the contingency tables were lower than 5 . 


\section{Results}

A total of 482 patients (283 females and 199 males) underwent esophagogastroduodenoscopy during the aforementioned time period. Patient demographics are presented in Table I. The main indication for endoscopy was dyspeptic syndrome (267 cases), anemia (58 cases) and 85 patients were examined for other symptoms. Indications for upper endoscopy are presented in Table II. Pathological endoscopic results were: 154 cases of erythematous gastritis, 90 cases of erosive gastritis, 62 cases of atrophic gastritis and 52 cases of peptic ulcer. Endoscopic findings are presented in Table III. The presence of Helicobacter pylori infection was assessed by histological examination of biopsies. Out of the 482 patients enrolled in this study , $139(28.8 \%)$ had histologic evidence of Helicobacter pylori infection.

We found a significant correlation of Helicobacter pylori infection with both, endoscopic $(\mathrm{p}=0,0008)$ and histologic $(\mathrm{p}=0,0181)$ evidence of atrophic gastritis (Table IV).

Table I. Demographic characteristics (482 patients)

\begin{tabular}{ccc}
\hline & & $\mathrm{N}(\%)$ \\
\hline Gender & Females & \\
& Males & $283(58,7 \%)$ \\
Age group & $199(41,2)$ \\
$20-29$ & $16(3,3 \%)$ \\
$30-39$ & $55(11,4 \%)$ \\
$40-49$ & $76(15,7 \%)$ \\
$50-59$ & $102(21,1 \%)$ \\
$60-69$ & $141(29,2 \%)$ \\
$70-79$ & $71(14,7 \%)$ \\
$>80$ & $21(4,3 \%)$ \\
\hline
\end{tabular}

Table II . Indication for esophagogastroduodenoscopy

\begin{tabular}{lc}
\hline & $\mathrm{N}(\%)$ \\
\hline Dyspepsia & $267(55,3 \%)$ \\
Anemia & $58(12 \%)$ \\
Gastrointestinal bleeding & $12(2,4 \%)$ \\
Reflux symtoms & $79(16,3 \%)$ \\
Other $^{*}$ & $85(17,6 \%)$ \\
\hline${ }^{*}$ Other indications include abdominal pain, diarrhea, nausea and vomiting
\end{tabular}

Table III. Endoscopic findings of gastric evaluation

\begin{tabular}{lc}
\hline & $\mathrm{N}(\%)$ \\
\hline Erythematous gastritis & $154(31,9 \%)$ \\
Normal & $10(2,8 \%)$ \\
Atrophic gastritis & $62(12,8 \%)$ \\
Erosive gastritis & $90(18,6 \%)$ \\
Ulcer (gastric) & $52(10,7 \%)$ \\
Other & $124(25,7 \%)$ \\
\hline * Other findings include mucosal nodularity, gastric polyps, masses
\end{tabular}

Out of the 482 patients endoscopically examined, 137 had gastric intestinal metaplasia at histological examination, with a prevalence of $28.4 \%$. A similar distribution between gender was observed with a significant increase of gastric intestinal metaplasia with age (chi-square for linear trend 23.09, $\mathrm{p}=0.0001$ ). (Table V). Regarding the indication for upper endoscopy, the prevalence of gastric intestinal metaplasia was: $17 \%$ among patients with dyspeptic syndrome, $2 \%$ in patients with anemia and $5 \%$ in patients examined for other symptoms. No significant statistical association was noticed $(\mathrm{p}=0.32)$.
Gastric interstinal metaplasia was found at endoscopy in $69 \%$ of patients with atrophic gastritis (43 of 62), compared to $36 \%$ in patients with gastric ulcers (19 of 52) and $23 \%$ in those with erythematous gastritis (31 of 154).

We found a positive correlation between gastric ulcer at endoscopic examination and the histological evidence of gastric atrophy $(\mathrm{p}=0,0418)$. Also gastric intestinal metaplasia was significantly associated with atrophic gastritis $(\mathrm{p}=$ $0,0001)$, and erythematous gastritis $(\mathrm{p}=0,0079)$, while there was no association with erosive gastritis $(p=0,24)$ and peptic ulcer $(\mathrm{p}=0,19)$ (Table VI).

\section{Disscussions}

The primary aim of this study was to determine the prevalence of gastric intestinal metaplasia in patients investigated by esophagogastroduodenoscopy for different symptoms and its clinical and endoscopical characteris-

Table IV. Correlation of $\mathrm{H}$ pylori infection with endoscopic findings and histopathological results

\begin{tabular}{lccc}
\hline & \multicolumn{3}{c}{ Helicobacter pylori infection } \\
\hline Endoscopic findings & 7 & $11,2 \%$ & $\mathrm{p}=0,0008$ \\
Atrophic gastritis & 49 & $31,8 \%$ & $\mathrm{p}=0,33$ \\
Erythematous gastritis & 30 & $33 \%$ & $\mathrm{p}=0,30$ \\
Erosive gastritis & 19 & $36,5 \%$ & $\mathrm{p}=0,19$ \\
Peptic ulcer & & & \\
\hline Histopathological results & 13 & $17,3 \%$ & $\mathrm{p}=0,181$ \\
Atrophic gastritis & 39 & $28,4 \%$ & $\mathrm{p}=1,000$ \\
Gastric intestinal mataplasia & & &
\end{tabular}

Table V. Prevalence of gastric intestinal metaplasia according to age group (482)

\begin{tabular}{lcc}
\hline $\begin{array}{l}\text { Age group } \\
\text { (year) }\end{array}$ & $\begin{array}{c}\text { Patients } \\
(\mathrm{n})\end{array}$ & $\begin{array}{c}\text { Intestinal metaplasia } \\
\text { positive patients }(\% \mathrm{n})\end{array}$ \\
\hline $20-29$ & 16 & $0(0 \%)$ \\
$30-39$ & 55 & $2(3,6 \%)$ \\
$40-49$ & 76 & $18(23,6 \%$ \\
$50-59$ & 102 & $29(28,4 \%)$ \\
$60-69$ & 141 & $55(39 \%)$ \\
$70-79$ & 71 & $28(39,4 \%)$ \\
$\geq 80$ & 21 & $5(23,8 \%)$ \\
\hline
\end{tabular}

Table VI. Correlation between endoscopic findings and histopathological results

\begin{tabular}{lcc}
\hline & Atrophic gastritis & Gastric intestinal metaplasia \\
\hline Atrophic gastritis & 38 & 43 \\
$\mathrm{n}$ cases & $61,2 \%$ & $69,3 \%$ \\
percent & $<0,0001$ & 0,0001 \\
$\mathrm{p}$ value & 17 & \\
\hline Erythematous gastritis & $11 \%$ & 31 \\
n cases & 0,078 & $20,1 \%$ \\
percent & & 0,0066 \\
p value & 3 & \\
\hline Erosive Gastritis & $5,4 \%$ & 21 \\
n cases & 0,053 & $23,3 \%$ \\
percent & & 0,24 \\
p value & 8 & 19 \\
\hline Peptic ulcer & $8,88 \%$ & $36,5 \%$ \\
n cases & 0,0418 & 0,190 \\
percent & &
\end{tabular}


tics. Many studies published in the last years reported data regarding the prevalence of gastric intestinal metaplasia and its relationship with age and Helicobacter pylori infection. According to a recent metaanalysis, the prevalence rates of gastric intestinal metaplasia are in a wide range from $7.1 \%$ to $42.5 \%$, depending on diagnostic methods and countries [8]. In a study performed in the Netherlands, Craanen et al. detected gastric intestinal metaplasia in $25.3 \%$ of the 533 patients examined by upper endoscopy. The prevalence of gastric intestinal metaplasia was significantly higher in patients over 50 years $(31.9 \%)$ compared with those $<50$ years $(10.4 \%)$. Also they reported the highest prevalence of gastric intestinal metaplasia in the age group over 80 years [9]. Similar data were observed in Korea, where gastric intestinal metaplasia was observed in $12.5 \%$ of 4023 patients who underwent screening endoscopy. The prevalence of gastric intestinal metaplasia significantly increased with age from $3.4 \%$ in patients under 40 years to $17.4 \%$ in those $\geq 60$ years, with a predominance for males [10]. In a study from Italy published in 2005, Zullo et al found gastric intestinal metaplasia in $32.3 \%$ of 179 patients with Helicobacter pylori infection and peptic ulcer with a mean-age 69.5 years [11]. Similar to this reported data, in our study the prevalence of gastric intestinal metaplasia was $28.4 \%$ and increased significantly with age from $13.6 \%$ in patients $<50$ years to $34.9 \%$ in those $>50$ years. The association between gastric metaplasia and advanced age suggest a potential role of a chronic injury of the gastric mucosa in triggering the disease [12]. Although it is generally understood that the prevalence of gastric intestinal metaplasia and the risk of its progression is higher in males $[13,14]$, we found a similar distribution between gender in accordance with previous reported data $[15,16]$. As previously mentioned, Helicobacter pylori infection is considered to be an important initial step in gastric carcinogenesis, increasing the risk of developing gastric cancer at least six folds [17]. There are abundant data in the literature $[18,19]$ revealing an association of premalignant gastric lesions/conditions and Helicobacter pylori infection. In our study, we evaluated Helicobacter pylori infection only by histological examination of gastric biopsy specimens and the prevalence was $28.8 \%$. Our findings showed a significant correlation between Helicobacter pylori infection and histologic evidence of atrophic gastritis $(p=0,0181)$, this association being even stronger between infection and atrophic gastritis at endoscopic examination $(p=0,0008)$. This data emphasizes the role of Helicobacter pylori infection as initiator or promoter of gastric carcinogenesis. We did not find the same association between Helicobacter pylori infection and gastric intestinal metaplasia $(p=1.000)$. The main explanation is that at the final stage of the disease, gastric atrophy with intestinal metaplasia were very serious and determine an unfavorable environment for Helicobacter pylori, leading to reduction or disappearance of the organism [20]. Regarding the endoscopic findings, we found a positive corre- lation between erythematous gastritis and the histological evidence of gastric intestinal metaplasia $(\mathrm{p}=0.066)$, and also an even stronger association between atrophic gastritis and gastric intestinal metaplasia $(\mathrm{p}=0.0001)$. These associations were previously described by some authors [2123], they emphasized that the malignant transformation of gastric mucosa involves a temporary sequence starting with the acquisition of Helicobacter pylori infection.

\section{Conclusions}

Gastric intestinal metaplasia is frequently recorded in patients undergoing upper gastrointestinal endoscopy with biopsy sampling. The prevalence of gastric intestinal metaplasia varies widely between countries. In our study the overall prevalence of intestinal metaplasia was $28.4 \%$, considered to be a mean value compared to other data reported in the literature. We did not observe a predisposition of gastric atrophy or intestinal metaplasia for any gender. The presence of Helicobacter pylori is associated with increased risk of atrophic gastritis. Endoscopic findings like erythema and atrophy are strongly associated with gastric intestinal metaplasia emphasizing the importance of sampling biopsies.

\section{References}

1. Ferlay J, Shin HR, Bray F et al. Estimates of worldwide burden of cancer in 2008: GLOBOCAN 2008. Int J Cancer. 2010; 127:2893-2917.

2. Correa P, Piazuelo M. The Gastric Precancerous Cascade. J Clin Exp Pathol. 2013;3 (3):147.

3. Lauren P.The two histological main types of gastric carcinoma: diffuse and so-called intestinal-type carcinoma. Acta Pathol Microbiol Scand. 1965;64: 31-49.

4. Correa P. Human gastric carcinogenesis: a multistep and multifactorial process-first American Cancer Society award lecture on cancer epidemiology and prevention.Cancer research.1992;52:6735-6740.

5. González CA, Agudo A. Carcinogenesis, prevention and early detection of gastric cancer: where we are and where we should go. Int $\mathrm{J}$ Cancer. 2012;130:745-753.

6. Zullo A, Hassan C, Romiti A, Giusto M, Guerriero C, Lorenzetti R, Campo SM, Tomao S. Follow-up of intestinal metaplasia in the stomach: When, how and why. World J Gastrointest Oncol. 2012;4:30-36.

7. Whiting JL, Sigurdsson A, Rowlands DC, Hallissey MT, Fielding JW. The long term results of endoscopic surveillance of premalignant gastric lesions. Gut. 2002;50:378-381.

8. Park YH, Kim N. Review of Atrophic Gastritis and Intestinal Metaplasia as a Premalignant Lesion of Gastric Cancer. J Cancer Prev. 2015; 20:25-40.

9. Craanen, M. E.,Dekker W, Blok P et al. Intestinal metaplasia and Helicobacter pylori: an endoscopic bioptic study of the gastric antrum. Gut. 1992;33:16-20.

10. Joo YE, Park HK, Myung DS et al. Prevalence and risk factors of atrophic gastritis and intestinal metaplasia: a nationwide multicenter prospective study in Korea. Gut Liver.2013;7:303-310.

11. Zullo A, Gatta L, De Francesco V, et al. High rate of Helicobacter pylori eradication with sequential therapy in elderly patients with peptic ulcer: a prospective controlled study. Aliment Pharmacol Ther. 2005;21:14191424.

12. Tulassay Z, Stolte M, Engstrand L, et al. Twelve-month endoscopic and histological analysis following proton-pump inhibitor-based triple therapy in Helicobacter pylori-positive patients with gastric ulcers. Scand J Gastroenterol. 2010;45:1048-1058.

13. Leung WK, Lin SR, Ching JY, et al. Factors predicting progression of gastric intestinal metaplasia: results of a randomised trial on Helicobacter pylori eradication. Gut. 2004;53:1244-1249.

14. Eshmuratov A, Nah JC, Kim N, et al. The correlation of endoscopic and histological diagnosis of gastric atrophy. Dig Dis Sci. 2010;55:13641375 . 
15. Den Hoed C. M., B.C. van Eijck, L.G. Capelle, et al. The prevalence of premalignant gastric lesions in asymptomatic patients: predicting the future incidence of gastric cancer. Eur J Cancer. 2011;47:1211-1218.

16. Sonnenberg A, Lash $\mathrm{RH}$, Genta RM. A national study of Helicobactor pylori infection in gastric biopsy specimens.Gastroenterology. 2010;139:1894-1901.

17. Conteduca V, Sansonno D, Lauletta G, et al. H. pylori infection and gastric cancer: State of the art (Review). Int J Oncol. 2013;42:5-18.

18. Valle J, Gisbert JP. Helicobacter pylori infection and precancerous lesions of the stomach. Hepato-gastroenterology. 2000;48:1548-1551.

19. Haziri A, Juniku-Shkololli A, Gashi Z, et al. Helicobacter pylori infection and precancerous lesions of the stomach. Med Arh. 2010;64:248-249.
20. Zhang C, Yamada N, Wu YL, et al. Helicobacter pylori infection, glandular atrophy and intestinal metaplasia in superficial gastritis, gastric erosion, erosive gastritis, gastric ulcer and early gastric cancer. World $\mathrm{J}$ Gastroenterol. 2005;11:791-796.

21. Correa P. A human model of gastric carcinogenesis. Cancer Res. 1988;48:3554-3560.

22. Rozen P. Cancer of the gastrointestinal tract: early detection or early prevention? Eur J Cancer Prev. 2004;13:71-75.

23. Israel DA, Peek RM. Review article: pathogenesis of Helicobacter pyloriinduced gastric inflammation. Aliment Pharmacol Ther. 2011;15:12711290. 